\title{
Effect of $\Delta$-9-Tetrahydrocannabinol on the in Vitro Uptake of $\alpha$-Amino Isobutyric Acid by Term Human Placental Slices
}

\author{
STANLEY E. FISHER, MARK ATKINSON, AND BENEDICT CHANG \\ North Shore University Hospital, Cornell University Medical College, Manhasset, New York 11030
}

\begin{abstract}
Tetrahydrocannabinol (THC), the active component in marijuana smoke, crosses the placenta and is a potential fetotoxic agent. In both human and animal studies, the most consistent fetal effect of THC is intrauterine growth retardation. Since fetal somatic growth is dependent on placental transfer of nutrients, including essential amino acids, we studied the effect of THC upon the in vitro uptake of amino acid by term human placental slices. Uptake of $\alpha$-amino isobutyric acid was inhibited in a dose-dependent fashion, correlating with the log of the dose $(1-100 \mu \mathrm{M}$ THC; $r=0.945 ; p<0.01)$. Compared to control tissue, significant impairment of $\alpha$-amino isobutyric acid uptake began at $20 \mu \mathrm{M}$ THC. Similar results were found for valine. The time course (30-120 $\mathrm{min}$ ) for $\alpha$-amino isobutyric acid uptake showed linearity for both control and THC- $(50 \mu \mathrm{M})$ treated tissue, but there was a marked reduction in the THC slope. Uptake of $\alpha$-amino isobutyric acid was significantly reduced at all times. The sustained effect of THC was slightly, but significantly, reversed by removal of THC from the medium after 90 min of $50 \mu \mathrm{M}$ THC exposure. Only partial reversal may have been due to the 15- to 20-fold accumulation of THC in the placental tissue. Uptake kinetics showed noncompetitive inhibition with decreased Vmax: control Vmax $=51.66 \pm 6.26$ versus $50 \mu \mathrm{M}$ THC $=26.96 \pm 6.22(\mathrm{mmol} /$ liter intracellular water per $h)(p<0.01)$; and no change in diffusion constant $(\mathrm{Km})$ : control $\mathrm{Km}=0.78 \pm 0.08$ versus $50 \mu \mathrm{M}$ THC $=$ $0.80 \pm 0.09(\mathrm{mM})$. In addition, $50 \mu \mathrm{M}$ THC caused a modest increase in Kd, but the difference was not significant: control $\mathrm{Kd}=3.82 \pm 0.29$ versus $50 \mu \mathrm{M}$ THC $=5.19$ $\pm 1.03\left(\mathrm{~h}^{-1}\right)$. Using actively transported amino acids as an index, the results of these experiments suggest that THC may be placento-toxic. (Pediatr Res 21: 104-107, 1987
\end{abstract}

\section{Abbreviations}

THC, $\delta$-9-tetrahydrocannabinol

IUGR, intrauterine growth retardation

AIB, $\alpha$-amino isobutyric acid

Val, valine

EBSS, Earle's balanced salt solution

$R$, ratio

Kd, diffusion constant

Y, transport velocity

EM, electon microscopy

ANOVA, analysis of variance

Received November 21, 1985: accepted September 10, 1986.

Correspondence Stanley E. Fisher, M.D.. North Shore University Hospital, 300 Community Drive, Manhasset, NY 11030.

Supported in part by a grant from the NICHD HD 17375. S.E.F. is the recipient of a Research Scientist Development Award from the NIAAA AA 00074.
Marijuana is a commony used illicit drug. The major active component in marijuana smoke, THC, crosses the placenta (1, 2). Under in vitro conditions, THC can be cytotoxic $(3,4)$. Therefore, marijuana exposure during pregnancy carries the potential for producing negative developmental effects. Case reports in man have suggested that marijuana may be teratogenic, but maternal use of multiple drugs in some of those reports precluded determination of a causal effect specific for Cannabis (5-7). Furthermore, epidemiologic studies have not suggested a teratogenic effect $(8,9)$. Animal investigations of marijuana teratogenicity have been inconclusive, with the majority of evidence indicating teratogenicity occurs only if exposure is very early in pregnancy and the administered dose is very high (8). On the other hand, most of the animal studies have shown that intrauterine exposure to marijuana extract or THC is fetotoxic, resulting in low birth weight or IUGR (8). In man, one epidemiologic project has been able to identify marijuana smoking as a cause of IUGR, independent of other drugs (9).

Normal fetal growth requires a milieu in which adequate nutritional components are available for full expression of genetically determined cellular differentiation and proliferation. The fetus is dependent on an external supply of nutrients to develop properly. Throughout most of pregnancy, the placenta is the major source of nutrients via maternal-to-fetal transfer. One category of nutrients, amino acids, is vital to normal fetal growth. Essential neutral amino acids are transferred across the placenta by a stereo-specific, energy-dependent, membrane-associated, saturable active transport process (10). Impairment of this or any other vital placental cellular function by maternal use of xenobiotic may contribute to IUGR, as postulated for ethanol $(11,12)$. Therefore, we have examined the possibility that THC is placento-toxic. The effect of THC on in vitro uptake of neutral amino acids by term human placental slices is utilized as an index of this potential placento-toxicity.

\section{MATERIALS AND METHODS}

AIB and Val were obtained from Sigma Co. (S. Louis, MO). EBSS ( $\mathrm{pH}=7.4$ ) with glucose $(1 \mathrm{~g} /$ liter) and phenol red, was purchased from MA Bioproducts (Walkersville, MD). ${ }^{14} \mathrm{C}$-AIB, ${ }^{14} \mathrm{C}$-Val, and ${ }^{14} \mathrm{C}$-inulin were obtained from New England $\mathrm{Nu}$ clear Corp. (Boston, MA). THC was provided by the National Institute on Drug Abuse in glass ampules containing $10 \mathrm{mg}$ THC in $1 \mathrm{ml} 95 \%$ ethanol.

Term human placentae were obtained from healthy women at the time of vaginal delivery. All women denied the use of ethanol, tobacco, and marijuana. Each placenta was placed on ice and immediately transported to the laboratory for preparation of villous slices according to a modification of methods previously described $(13,14)$. Slices of villous tissue (20-50 mg pressed weight) were washed once in ice-cold saline and twice in EBSS. They were then preincubated at $37^{\circ} \mathrm{C}$ for $30 \mathrm{~min}$ in a sealed 
flask containing EBSS ( $2 \mathrm{ml} / \mathrm{slice}$ ), which had been aerated with $95 \% \mathrm{O}_{2} / 5 \% \mathrm{CO}_{2}$. The tissue was transferred to another flask of fresh, aerated EBSS for $15 \mathrm{~min}$, representing a second preincubation. The medium from this second preincubation contains modest amounts of endogenous placental protein. The THC added to the "final" incubation medium requires protein to hold it in suspension. Thus, some of the second preincubation medium was used to adjust the protein concentration of the final incubation medium to $2 \mathrm{mg} / \mathrm{dl}$ prior to addition of the THC.

THC in $95 \%$ ethanol was added to this final medium to achieve desired concentrations (corresponding amounts of $95 \%$ ethanol were added to control medium). For dose-response and timecourse experiments, the final medium was used for measurement of amino acid uptake in the presence or absence (control) of THC. For reversibility and kinetics experiments, only AIB uptake was determined. The final medium was divided into two batches. The first batch was used for $90 \mathrm{~min}$ of drug (or control) exposure, without any AIB present. This was followed by $60 \mathrm{~min}$ (reversibility) or $20 \mathrm{~min}$ (kinetics) of AIB uptake with or without THC.

Uptake of amino acid was measured by the method of Smith et al. (13) as modified by Fisher et al. (14). Each sealed 25-ml incubation flask contained $5 \mathrm{ml}$ of aerated final medium and two placental slices. The concentration of amino acid in the final medium was $125 \mu \mathrm{M}$ for AIB or $50 \mu \mathrm{M}$ for Val. Wet weight was determined after blotting and then pressing with a $2-\mathrm{kg}$ weight for $20 \mathrm{~min}$ at $4^{\circ} \mathrm{C}$. After correcting for extracellular water using the inulin space, uptake was expressed as the $\mathrm{R}$ of radioactivity in the intracellular water to radioactivity in the medium. For the kinetics experiments, the final concentrations of AIB in the medium ranged between $1.0 \mu \mathrm{M}$ and $50 \mathrm{mM}$. The $\mathrm{Kd}$ and $\mathrm{Y}$ were calculated according to the method of Akedo and Christensen (15), as described by Smith et al. (13). The other parameters were calculated from a Woolf-Augustinsson-Hofstee plot (16), with the negative slope representing the $\mathrm{Km}$ and the y-intercept the Vmax.

Light microscopy and transmission EM on fresh tissue and tissue exposed for 90 min to drug-containing or control medium were performed after fixation in either $10 \%$ formalin (light) or $2 \%$ glutaraldehyde in cacodylate buffer (EM). Protein was determined by the method of Lowry et al. (17).

Grouped data were analyzed by the $t$ test for paired data or by ANOVA. Differences between means were considered significant at $p<0.05$. These comparisions were performed on the Minitab Statistical Computing System (University Park, PA). Similarly, Minitab was utilized to compute correlation coefficients and linear regressions.

\section{RESULTS}

Light microscopy and EM did not show any difference in villous tissue between control and $50 \mu \mathrm{M}$ THC exposure. Under EM, the nuclei of the syncytiotrophoblast cells appeared less dense than those of the cytotrophoblasts after 90 min of incubation, but this was unrelated to drug treatment.

Using ${ }^{3} \mathrm{H}-\mathrm{THC}$ as a tracer, $25-30 \%$ of the THC in the medium was found to adhere to the glassware. This proportion of loss to glassware adherence was constant throughout the range of nominal THC concentrations in the medium. Conversely, THC levels in the tissue were 15 - to 20 -fold elevated relative to the nominal medium concentrations. With $2 \mu \mathrm{M}$ THC in the medium $(2$ $\mathrm{nmol} \mathrm{THC} / \mathrm{ml}$ medium), the tissue THC concentration was 40.5 $\pm 3.5 \mathrm{nmol} / \mathrm{g}$ pressed weight $(n=6$; with correction for extracellular space using ${ }^{14} \mathrm{C}$-inulin); at $5 \mu \mathrm{M}$ THC in the medium it was $75.8 \pm 7.9 \mathrm{nmol} / \mathrm{g}$; at $50 \mu \mathrm{M}$ THC in the medium it was $847.1 \pm 78.1 \mathrm{nmol} / \mathrm{g}$. Following $60 \mathrm{~min}$ of "washout" with THCfree medium, the tissue concentration was reduced by only 18.1 $\pm 2.4 \%$.

Human placental slice uptake of AIB, in the presence of THC, was impaired in a dose dependent fashion, from 1.0 to $100 \mu \mathrm{M}$ THC (Fig. 1). Compared to control uptake, significant inhibition occurred initially with $20 \mu \mathrm{M}(p<0.05$, ANOVA). With $50 \mu \mathrm{M}$, uptake was reduced by nearly $30 \%$ ( $p<0.01$, ANOVA). The effect of $50 \mu \mathrm{M}$ THC on valine uptake was tested in six placentae and followed the same pattern: control $=7.73 \pm 0.66 ; 1 \mu \mathrm{M}$ $\mathrm{THC}=7.54 \pm 0.68 ; 5 \mu \mathrm{M} \mathrm{THC}=7.45 \pm 0.51 ; 10 \mu \mathrm{M}$ THC $=$ $7.06 \pm 0.60 ; 50 \mu \mathrm{M}$ THC $=5.83 \pm 0.64$. The $50 \mu \mathrm{M}$ treatment was significantly lower than control ( $p<0.05$; ANOVA).

To see how quickly THC might alter AIB uptake, and whether or not the effect might be continuous and additive over the short term, slices were exposed to $50 \mu \mathrm{M}$ THC for 30-120 min (Fig. 2). Uptake was linear for both control and THC, but the slope was reduced for THC exposed tissue. Inhibition of AIB uptake was seen at $30 \mathrm{~min}$ and continued throughout $(p<0.05$, paired $t$ test). Thus, uptake reduction was relatively rapid and continuous. In five placentae, potential reversibility was tested by exposing tissue to $50 \mu \mathrm{M}$ THC for $90 \mathrm{~min}$, followed by 60 -min AIB uptake with (continuous exposure) or without (potential reversal) $50 \mu \mathrm{M}$ THC. Control tissue was treated identically, without any THC exposure at any time. There was slight reversal of the 50 $\mu \mathrm{M}$ THC effect on AIB uptake. The continuous exposure tissue

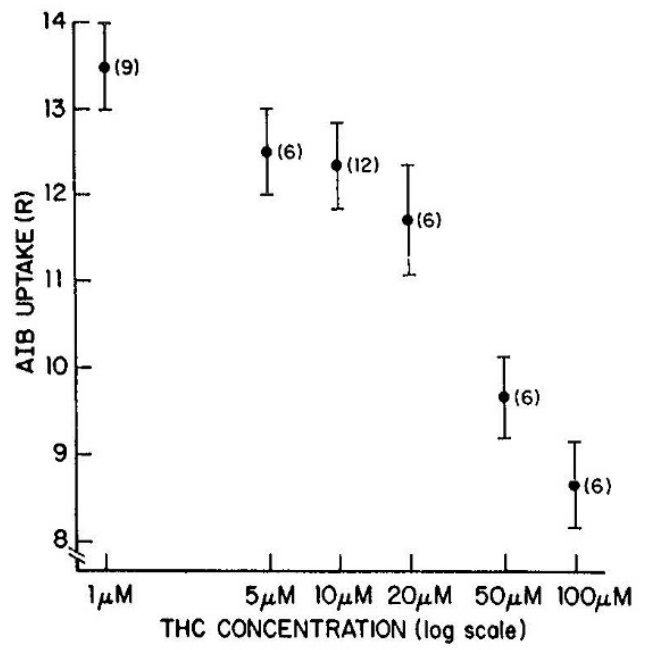

Fig. 1. Dose response of 90 -min AIB uptake versus the $\log$ of the THC concentration in the medium $(1-100 \mu \mathrm{M})$. AlB uptake is expressed as the ratio $(R)$ of the intracellular AIB concentration to the concentration in the medium. Data are the mean \pm SE. $(N)=$ number of placentae. While there appears to be a plateau from $5-10 \mu \mathrm{M}$ with a steep response thereafter, there is also a strong linear correlation between the log dose and inhibition of AIB uptake $(r=0.945 ; p<0.01)$. The regression equation is $\mathrm{y}=14.1-2.42 \mathrm{x}$.

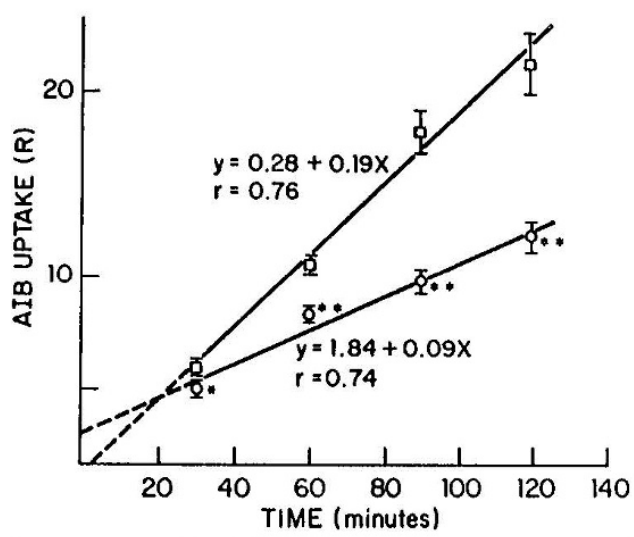

Fig. 2. Time-course (30-120 min) of AIB uptake with $50 \mu \mathrm{M}$ THC (O) versus control ( $\square)$. All data are mean uptake $R \pm S E$. Uptake of AIB continues to increase linearly for both groups. However, the slopes show that there is sustained inhibition of AIB uptake by $50 \mu \mathrm{M} \mathrm{THC}$, beginning at the $30 \mathrm{~min}\left({ }^{*} p<0.05 ;{ }^{* *} p<0.01\right)$. 
had uptake which was $72.0 \pm 6.6 \%$ of matched controls $(p<$ 0.01 , paired $t$ test). Uptake for potential reversal tissue was 83.2 $\pm 7.0 \%$, significantly lower than matched controls $(p<0.01)$, but higher than the continuous exposure $(p<0.05)$.

The results of the kinetics experiments are illustrated by the plot of $\mathrm{Y}$ versus $\mathrm{Y} / \mathrm{C}_{\mathrm{o}}$ for one representative placenta (Fig. 3). The plot demonstrates noncompetitive inhibition by $50 \mu \mathrm{M}$ THC, in that the $\mathrm{Km}$ (negative slope) is essentially unaltered, while there is a $50 \%$ fall in the Vmax (y intercept). When the data from five placentae are compared (Table 1), there is a significant decrease in $V \max (p<0.01$, paired $t$ test $)$, but no significant change in $\mathrm{Km}$. In addition, THC exposure caused a slight increase in $\mathrm{Kd}$ but the difference was not significant (paired $t$ test).

\section{DISCUSSION}

Using exclusively human placental tissue, our results indicate that THC has the potential to impair maternal-to-fetal transfer of essential amino acids. The primary substrate for the studies was AIB, an actively transported, nonmetabolized amino acid which is frequently used as a model for sodium-dependent neutral amino acid uptake by the human placenta. For comparison, limited experiments were also performed with Val, an actively transported, mostly sodium-independent amino acid. Under our in vitro conditions, term human placenta slice uptake of AIB is linear for several hours $(13,14)$. Yet, within $30 \mathrm{~min}$, THC began to impair AIB uptake in a dose-dependent fashion. Similar results were obtained with Val. The effect of THC on both amino acid systems suggests a generalized impairment of cellular function, with amino acid uptake serving as an index of cytotoxicity.

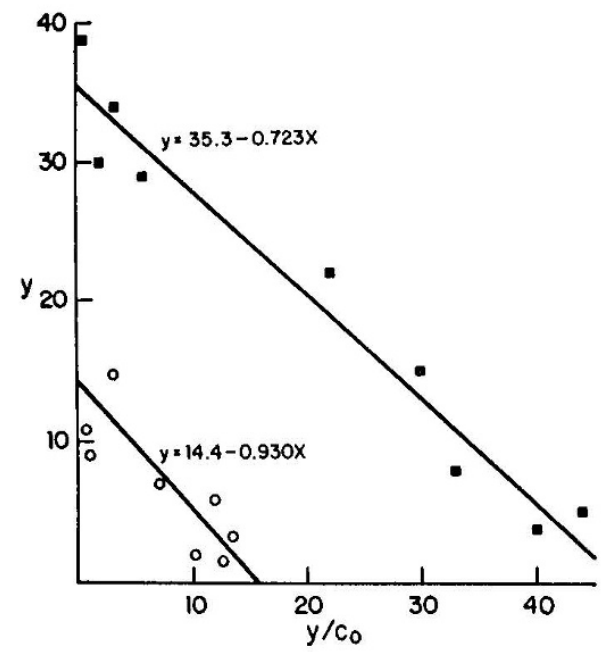

Fig. 3. Kinetics of AIB uptake with $50 \mu \mathrm{M}$ THC (O) versus control (๘). In these data from a single placenta, velocity of uptake $(Y)$ is plotted against velocity divided by concentration of AIB in the medium $\left(Y / C_{0}\right)$. With $50 \mu \mathrm{M}$ THC there is a fall in Vmax (y intercept) and essentially no change in $\mathrm{Km}$ (negative slope). These findings suggest noncompetitive inhibition of AIB uptake by $50 \mu \mathrm{M}$ THC (see also Table 1).

Table 1. AIB uptake kinetics (mean \pm SE)

\begin{tabular}{lccc}
\hline \multicolumn{4}{c}{$\begin{array}{c}\text { Vmax } \\
(\mathrm{mmol} / \mathrm{liter}\end{array}$} \\
\multicolumn{1}{c}{ Treatment } & $\mathrm{ICW} / \mathrm{h})$ & $\mathrm{Km}(\mathrm{mM})$ & $\mathrm{Kd}\left(\mathrm{h}^{-1}\right)$ \\
\hline Control $(n=5) \dagger$ & $51.66 \pm 6.26$ & $0.78 \pm 0.08$ & $3.82 \pm 0.29$ \\
$50 \mathrm{uM}$ THC $(n$ & $26.96 \pm 6.22 \neq$ & $0.80 \pm 0.09$ & $5.19 \pm 1.03$ \\
$=5)$ & & & \\
\hline
\end{tabular}

\footnotetext{
* Intracellular water.

$\dagger$ No. of placental.

$\ddagger p<0.01$; paired $t$ test.
}

Inhibition of either AIB or Val uptake during our short-term incubations required relatively high concentrations of THC $(>10$ $\mu \mathrm{M})$ in the medium. Although adherence to glassware reduced the nominal concentration, it was still in excess of that found in plasma. For example, inhalation of THC from one marijuana cigarette may result in a peak blood level of approximately 0.3 $\mu \mathrm{M}$ (18). On the other hand, our inhibitory concentrations are similar to those used by other investigators to demonstrate the in vitro effects of THC on cellular metabolism and transport of macromolecular precursors $(4,19-22)$. Specifically, $10^{-4}$ to $10^{-5}$ M THC inhibits uptake of AIB (20) and leucine (22) by cultured lymphocytes. Furthermore, THC and its metabolites are lipophilic and accumulate in the body, especially within fatty tissue and cell membranes (23-26). The placenta in particular, is a tissue that tends to accumulate THC in vivo (27). This was paralleled by the results of our in vitro observations where tissue concentrations were in excess of those in the medium.

A similar interpretative problem exists for the placento-toxicity of ethanol: very high concentrations of ethanol are required to acutely alter AIB uptake by human placental slices (14); yet the primate placenta (the experimental model closest to the human) and rodent placenta show diminished amino acid uptake when the animals are chronically exposed to ethanol (27-29). As to the ethanol in which the THC was supplied, control tissue was similarly treated, and the highest ethanol concentration achieved, $240 \mathrm{mg} / \mathrm{dl}$ for $100 \mu \mathrm{M}$ THC, is well below that which acutely alters AIB uptake (>1000 mg/dl) (14).

Unlike ethanol, the short-term effects of THC exposure on human placental AIB uptake are only modestly reversed by simply removing the drug. This may be related to cellular accumulation of THC since high tissue levels remain despite $60 \mathrm{~min}$ of washout. In vitro, the extremely low aqueous solubility of THC would cause it to remain bound to membrane lipids and possibly intracellular protein $(26,31,32)$. Furthermore, the relatively low protein concentration in the medium would also favor tissue retention since in vitro toxicity of $\mathrm{THC}$ has been shown to correlate inversely with the protein concentration of the medium (22).

Accumulation of THC within the tissue and subsequent interference with AIB uptake is supported by the kinetics studies. Specifically, there was evidence of noncompetitive inhibition, as indicated by the fall in Vmax without any change in $\mathrm{Km}$. No specific mechanism can be inferred from our data, but other studies have suggested that THC alters cell function by membrane changes $(20,31)$, diminished glycolysis (33), and decreased Na,K-ATPase activity (34-36). All three could be applicable to our findings, in that placental uptake of AIB is dependent on putative membrane-bound carriers, an aerobic source of energy and Na,K-ATPase (10). The effect of THC on Val, which is not dependent on $\mathrm{Na}, \mathrm{K}-\mathrm{ATPase}$, would argue for more nonspecific metabolic or membrane changes. The latter is an important general mechanism for THC cytotoxicity (37). Although there was a small increase in $\mathrm{Kd}$ with $\mathrm{THC}$ exposure, implying an alteration in membrane permeability, the difference was not significant. Back diffusion or cellular leakage of AIB is not likely to have been responsible for the net decrease in AIB uptake associated with THC exposure (20).

The results of our in vitro studies indicate that THC has the potential to be placento-toxic in the human. Using actively transported amino acids as an index, it is suggested that THC could accumulate in the placenta and interfere with transport of essential amino acids or other macromolecular precursors. Hence, THC placento-toxicity could deprive the fetus of certain nutrients required for normal intrauterine growth. However, because our in vitro studies required very high THC concentrations to demonstrate toxicity, animal investigations are underway to evaluate the placento-toxicity of THC at blood concentrations similar to those found in man. Furthermore, the in vitro findings with the placenta do not preclude the possibility of direct THC feto-toxicity. Since THC crosses the placenta, both placento- and 
feto-toxicity could play a role in the IUGR seen with human use of THC during pregnancy.

\section{REFERENCES}

. Idanpaan-Heikkila J, Fritchie GE, Englert LF, Ho BT, McIsaac WM 1969 Placental transfer of ${ }^{3} \mathrm{H}$-1-delta-9-tetrahydro-cannabinol. $\mathrm{N}$ Engl J Med $281: 330$

2. Martin BR. Dewey WL. Harris LS, Beckner JS $1977^{3}$-delta-9-tetrahydrocannabinol distribution in pregnant dogs and their fetuses. Res Commun Chem Pathol Pharmacol 17:457-470

3. Banchereau J, Desoize B, Leger C, Nahas G 1979 Inhibitory effects of delta-9tetrahydrocannabinol and other psychotropic drugs on cultured lymphocytes. In: Nahas G, Paton W (eds) Marijuana: Biological Effects. Pergamon Press, New York, pp 129-144

4. Mon MJ, Jansing RL. Daggett S, Stein JL, Stein GS 1978 Influence of delta9-tetrahydrocannabinol on cell proliferation and macromolecular biosynthesis in human cells. Biochem Pharmacol 27:1757-1765

5. Hecht F. Beas R, Lees N. Jolly H, Roberts P 1968 Lysergic acid diethylamide and cannabis as possible teratogens in man. Lancet 2:1087

6. Carakushansky G, Neu RL, Gardner LI 1969 Lysergide and cannabis as possible teratogens in man. Lancet 1:150

7. Qazi QH, Mariano E, Beller E, Milman D, Crombleholme W 1982 Is marihuana smoking fetotoxic? Pediatr Res 16:272A

8. Abel EL 1983 Marihuana, Tobacco, Alcohol and Reproduction. CRC Press, Boca Raton, pp 31-33

9. Hingson R, Alpert JJ, Day N, Dooling E, Kanye H, Morelock S, Oppenheimer E. Zuckerman B 1982 Effect of maternal drinking and marijuana use on fetal growth and development. Pediatrics 70:539-546

10. Miller RK. Berndt WD 1975 Mechanisms of transport across the placenta: an in vitro approach. Life Sci 16:7-30

11. Henderson GI 1982 Maternal ethanol consumption and fetal development: two potential mechanisms. Dev Pharmacol Ther 4 (suppl 1):66-78

12. Fisher SE. Atkinson M, Burnap JK, Jacobson S, Sehgal PK, Scott W, Van Thicl DH 1982 Ethanol-associated selective fetal malnutrition: a contributing factor in the fetal alcohol syndrome. Alcoholism (NY) 6:197-201

13. Smith CH, Adcock EW. Teasdale F, Meschia G, Battaglia FC 1973 Placental amino acid uptake: tissue preparation, kinetics and preincubation effect. Am J Physiol 224:558-564

14. Fisher SE, Atkinson M, Van Thiel DH, Rosenblum E, David R, Holzman I 1981 Selective fetal malnutrition: the effect of ethanol and acetaldehyde upon in vitro uptake of alpha amino isobutyric acid by human placenta. Life Sci 29:1283-1288

15. Akedo H. Christensen HN 1962 Nature of insulin action on amino acid uptake by the isolated diaphragm. J Biol Chem 237:118-122

16. Segel IH 1975 Biochemical Calculations. John Wiley and Sons. New York, pp 246-273

17. Lowry OH. Rosebrough NJ, Farr AL, Randall RJ 1951 Protein measurement with the Folin phenol reagent. J Biol Chem 193:265-275

18. Nahas GG 1979 Current status of marujuana research. JAMA 242:2775-2778

19. Dvilansky A. Zolotov Z, Herzliker B. Nathan I 1984 Effects of ethanol, CBD and delta-1-THC on proliferation of K-562 cells. Int J Tissue Reac 6:409_ 412

20. Desoize B, Leger C, Nahas G 1979 Plasma membrane inhibition of macromolecular precursor transport by THC. Biochem Pharmacol 28:113-118

21. Jering H, Toro-Goyco E 1979 Effect of $\left({ }^{-}\right)$-delta-9-tetrahydrocannabinol on nucleoside and amino acid uptake in reuber-H-35 hepatoma cells. Mol Pharmacol 15:627-632

22. Nahas GG, Morishima A Desoize 1977 Effects of cannabinoids on macromolecular synthesis and replication of cultured lymphocytes. Fed Proc 36:17481752

23. Lemberger L, Tamarkin NR, Axelrod J, Kopin IJ 1971 Delta-9-tetrahydrocannabinol: metabolism and disposition in long term marhuana smokers. Science 173:72-74

24. Kreuz DS, Axelrod J 1973 Delta-9-tetrahydrocannabinol: localization in body fat. Science 179:391-393

25. Hunt A, Jones RT 1980 Tolerance and disposition of tetrahydrocannabinol in man. J Pharmacol Exp Ther 215:35-44

26. Leuschner JTA, Wing DR, Harvey DJ, Brent GA, Dempsey CE, Watts A Paton WDW 1984 The partitioning of delta-1-tetrahydrocannabinol into erythrocyte membranes in vivo and its effect on membrane fluidity. Experientia 40:866-868

27. Harbison RD, Mantilla-Plata B 1972 Perinatal toxicity, maternal distribution and placental transfer of tetrahydrocannabinol. J Pharmacol Exp The $140: 446-453$

28. Fisher SE, Atkinson M, Jacobson S, Sehgal P, Burnap J, Holmes E, Teichberg S, Kahn E, Jaffe R, Van Thiel DH 1983 Selective fetal malnutrition: The effet of in vivo ethanol exposure upon in vitro placental uptake of amino acids in the non-human primate. Pediatr Res 17:704-707

29. Lin GWJ 1981 Effect of ethanol feeding during pregnancy on placental transfer of alpha amino isobutyric acid in the rat. Life Sci 28:595-601

30. Henderson GI, Patwardhan RV, McLeroy S, Schenker S 1982 Inhibition of placental amino acid uptake in rats following acute and chronic ethanol exposure. Alcoholism (NY) 6:495-505

31. Roth SH, Williams PJ 1979 The non-specific membrane binding properties of delta-9-tetrahydrocannabinol and the effects of various solubilizers. J Pharm Pharmacol 31:224-230

32. McCallum NK, Eastwood ME 1978 In vivo binding of delta-1-tetra-hydrocannabinol and cannabinol to rat serum proteins. J Pharm Pharmacol 30:384386

33. Husain S, Lame MW 1981 Inhibitory effects of delta-9-tetra-hydrocannabinol on glycolytic substrate in rat testis. Pharmacol 23:102-112

34. Laurent B, Roy PE, Gailis 1974 Inhibition by delta-1-tetrahydro-cannabinol of a $\mathrm{Na}^{+}-\mathrm{K}^{+}$transport ATPase from rat ileum. Preliminary report. Can J Physiol Pharmacol 52:1110-1113

35. Toro-Goyco E, Rodriguez MB, Preston AM 1978 On the action of delta-9 tetrahydrocannabinol as an inhibitor of sodium and potassium-dependent adenosine triphosphatase. Mol Pharmacol 14:130-137

36. Bloom AS, Haavik CO, Strehlow D 1978 Effects of delta-9-tetra-hydrocannabinol on ATPases in mouse brain subcellular fractions. Life Sci 23:13991404

37. Martin BR 1986 Cellular effects of cannabinoids. Pharmacol Rev 38:45-74 